\title{
Heart or lung failure: what causes exertional, high altitude, and cold immersion pulmonary oedema?
}

Most cardiologists regard the normal heart as an organ that cannot be damaged by physiological loads. The normal heart, they would claim, cannot fail from overwork or fatigue provided it is supplied with sufficient fuel and oxygen. It pumps out what is returned to it and adjusts its output to the preload (filling volume and pressure) and afterload (peripheral resistance) without suddenly failing. Failure occurs from the heart dilating and raising its filling pressure and the pulmonary venous and capillary pressures to levels where the lungs fill with fluid.

\section{Sucking and blowing}

The amphibian heart can suck as well as blow. Filling of the left ventricle in diastole may not be as passive as pressure measurements would suggest. An isolated frog's left ventricle with the atria and valves removed and placed in a bath of nutrient oxygenated Ringer solution continues to beat normally for some time. Each time the ventricle contracts it pushes fluid out through the outflow tract and jets backwards, but in diastole it does not remain stationary, as would be expected if it filled passively, but creeps forwards as the ventricle sucks in the fluid.

Whether the human heart sucks as well as blows at rest, and indeed whether it sucks as well as blows on maximum exercise is debatable.

Cardiac outputs of $30-40$ litres $\cdot \mathrm{min}^{-1}$ with heart rates up to 200 are not easily or ethically studied in elite athletes and evidence has to accumulate from "natural experiments" or medical "anecdotes" as to how the heart behaves under extremes.

\section{Exertional pulmonary oedema in runners - an early theory}

Back in 1979 McKechnie and colleagues ${ }^{1}$ described two highly trained black athletes with apparently normal hearts, who both completed the first half of the 1978 South African Comrades marathon $(90 \mathrm{~km})$ at their normal pace, but then over the second half, after running continuously for several hours developed increasing breathlessness, haemoptysis, and blood stained frothy sputum. They both completed the $90 \mathrm{~km}$ but had to be admitted to hospital and had clinical and radiological signs of pulmonary oedema which cleared over the next 24 hours. They both recounted previous similar episodes after prolonged exertion.

Subsequent cardiological tests, including ECG, echocardiogram, coronary angiography, and left ventriculography showed no abnormality. Both had superior exercise tolerance and could exercise for some time at much higher intensity than their pace in the Comrades marathon without any problems.

The authors suggested a defect of cardiac filling (relaxation) due to a metabolic problem that developed after prolonged exertion, not demonstrable at rest, and which impaired diastolic compliance.

Perhaps the ventricles had stopped sucking. Is there any evidence for such a defect of basic cardiac behaviour?

\section{The lung theory}

Subsequent years have been remarkably free of similar anecdotes of pulmonary oedema associated with prolonged exertion in subjects with normal hearts "doing it standing up at sea level", but a recent paper from Israel describing pulmonary oedema and haemopysis in apparently fit naval swimmers who had drunk up to 5 litres of fluid, as well as experience of high altitude pulmonary oedema, ${ }^{3-5}$ cold induced immersion pulmonary oedema, ${ }^{6}$ and haemoptysis in race horses, ${ }^{7}$ all fit with a theory proposed by West and Mathieu-Costello, ${ }^{8}$ who suggest that these conditions are caused by damage to the lungs from stress failure of pulmonary capillaries occurring on exertion in unusual circumstances. The stresses on the capillary basement membrane can become as great in terms of tissue loading as those on the aorta.

The stress failure occurs patchily and makes the pulmonary capillaries leaky, allowing high molecular weight protein oedema fluid into the interstitium of the lungs and on occasion producing haemoptysis. (High molecular weight proteins have been washed out of the lungs of victims of high altitude pulmonary oedema. These would not be present with a simple transudate.) 


\section{High altitude pulmonary oedema}

High altitude pulmonary oedema is a potentially lethal condition presenting usually above $2500 \mathrm{~m}$ in recreational tourers and climbers, particularly those arriving at altitude by air, without adequate time to acclimatise. Experienced climbers may succumb at high altitude even after acclimatisation. The victim presents with dyspnoea and cough with blood stained frothy sputum and clinical signs of pulmonary oedema which look patchy on chest $x$ ray. The mechanism is thought to be related to the development of hypoxic pulmonary vasoconstriction causing pulmonary hypertension. Because of the patchy nature of the vasoconstriction, some of the pulmonary capillaries are exposed to much higher pressures than others, causing stress failure of the capillaries with leakage of fluid containing high molecular weight proteins into the lungs. The pulmonary oedema causes further hypoxia and the patient may become desperately ill and die from rapidly progressive pulmonary oedema unless treated promptly with diuretics, oxygen, and preferably recompression by evacuation to lower altitude..$^{3-5}$

\section{Cold immersion pulmonary oedema}

Cold induced pulmonary oedema is less generally recognised but was described in 1989 by Wilmshurst et al who investigated a group of scuba divers and swimmers. ${ }^{6}$ These swimmers appeared experimentally to have an abnormally dramatic response to cold and possibly raised partial pressure of oxygen (scuba diving). All had developed symptoms of severe breathlessness, some with haemoptysis while swimming or diving in cold water (UK waters at $<12{ }^{\circ} \mathrm{C}$ ) but were symptom-free swimming in warmer water and were apparently free of cardiac or respiratory disease. They all had had a diagnosis of pulmonary oedema made after cold immersion and some had several recurrences under similar circumstances, or even while surface swimming in cold water. The authors postulated a large increase in preload (venoconstriction ) and afterload (arterial constriction) overloading and compromising the heart. Many of the subjects became hypertensive during follow up, but otherwise had normal hearts.

\section{Warm immersion "drinking too much" pulmonary oedema}

The Israeli naval "unintentional physiological experiment" shows that additional factors may trigger the same phenomenon in the absence of high altitude and cold.

Thirty fit young men were sent off on a $2.4 \mathrm{~km}$ open water sea swim with a water temperature of $23{ }^{\circ} \mathrm{C}$ using swim fins. Because of the high heat load expected they were instructed to drink large quantities of water and on average consumed about 5 litres in the two hours preceeding the swim. Eight developed symptoms of pulmonary oedema with cough, dyspnoea, and haemoptysis. Two had recurrence of symptoms while swimming after apparent recovery. The extraordinary preload (5 litres of fluid) plus the horizontal posture and squeeze effect of immersion on venous capacitance plus the antidiuretic effect of severe exercise all seem to have combined to produce this very high "strike rate" for pulmonary oedema with exercise.

\section{Stress failure of pulmonary capillaries in race horses}

In support of their 1992 hypothesis on stress failure of pulmonary capillaries, West and Mathieu Costello quote the haemodynamics of race horses in which the maximum oxygen uptake per $\mathrm{kg}$ body weight is twice that of the human and in which measurements of mean pulmonary artery pressure can reach $80-120 \mathrm{~mm} . \mathrm{Hg}$ and left atrial pressure as much as $70 \mathrm{~mm} \mathrm{Hg}{ }^{9}$ Haemoptysis is a common symptom in the thoroughbred racehorse and can be catastrophic. ${ }^{7}$

No one has made similar measurements on Olympic scullers, but the pulmonary capillary stress failure theory unifies and explains all these phenomena, particularly the tendency for the symptoms to recur even though the heart appears normal; the leaky lungs take time to recover.

\section{Posture}

According to this theory the heart is, after all, an innocent bystander in these types of pulmonary oedema and may be sucking as usual so don't blame the left ventricle, it is doing its best! But if the heart is damaged, exercise standing up! Pulmonary oedema during exercise testing is seven times more frequent using a bicycle ergometer in the supine than in the sitting position. ${ }^{10}$

Dan Tunstall Pedoe

Cardiac Department,

St Bartholomew's Hospital, London ECIA 7BE

\section{References}

1 McKechnie JK, Leary WP, Noakes TD, Kallmeyer JC, MacSearraigh ETM, Olivier LR. Acute pulmonary oedema in two athletes during a 90$\mathrm{km}$ running race. S Afr Med J 1979; 56:261.

2 Weiler-Ravel D, Shupak A, Goldenberg J, et al. Pulmonary oedema and haemoptysis induced by strenuous swimming. BMJ 1995 ; 311 : 361.

3 Pines A. Pulmonary oedema of mountains. BMJ 1972; iii: 642.

4 Radford P. High-altitude oedema presenting as coma. BMJ 1973; iii : 294. 
5 Clarke CR. Care of the mountaineer. Practitioner 1976; 217: 235.

6 Wilmshurst PT, Nuri M, Crowther A, MM. W-P. Cold induced pulmonary oedema in scuba divers and swimmers and subsequent devlopment of hypertension. Lancet 1989; i: 62.

7 O'Callaghan MW, Pascoe JR, Tyler WS, Mason DK. Exercise induced pulmonary haemorrhage in the horse: results of a detailed clinical, postmortem and imaging study. V. Conclusions and implications. Equine Vet J 1987; 19: 428-34.

8 West JB, O. M-C. Stress failure of pulmonary capillaries: role in lung and heart disease. Lancet 1992; 340 : 762.

9 Jones JH, Smith BL, Birks EK, Pascoe JR, Hughes TR. Left atrial and pulmonary arterial pressures in exercising horses [abstr]. FASEB J 1992; 6 : A2020.

10 Kaltenbach M, Schere D, Dowinsky S. Complications of exercise testing. A survey in three German speaking countries. Eur Heart J 1982; 3 : 199-202.

\section{Obituary died 18 July 1995 \\ A pioneer of British sports medicine and soft tissue injury}

Dr John G P Williams, born 15 September 1932,

Sports medicine and rehabilitation medicine have lost one of their true pioneers with the untimely death of John Williams from cancer. Typically he kept very quiet about his terminal illness, not wanting it publicised, and bravely working right until the end.

John had had an operation for cancer in March 1993, but already had metastases. Chemotherapy and uncertainty followed but he bravely battled on with a heavy load of consultations, operations, lectures and publications, operating until a month before he died and seeing patients as late as a week before at Bon Secours Hospital in Buckinghamshire. Mercifully when the end came, it was fairly quick. His colleagues receiving letters and referrals from him had no idea how ill he was.

He gave a lecture in February at the National Sports Medicine Institute which he began by asking the audience in slightly combative style what was the major problem affecting the Achilles tendon. 'It's the people who treat it', he said, and went on to explain that although it was a major interest of his, he did not claim to know how to treat all its problems, whereas many 'experts' - through ignorance - did.

John was a rather private individual. Son of a Royal Navy Surgeon Commander, he won a scholarship to Caius Cambridge from Beaumont College, Windsor, and qualified from St Mary's, Paddington in 1956. After this he gained a diploma in obstetrics and gynaecology and in 1967 a diploma in physical medicine which led him on to his life's work, rehabilitation and sports medicine. He started an athletes' clinic at the Middlesex Hospital in the 1960s, became a consultant in rehabilitation medicine at Mount Vernon Hospital in 1965, and shortly after was made medical director of Farnham Park Rehabilitation Centre which won an international reputation for excellence. He treated athletes there for more than 25 years and then moved the work to the Bon Secours Hospital when Farnham Park was closed.
A keen sportsman himself, he won junior single sculls events on the Serpentine during the Festival of Britain (1951) and was a Leander Club member. He also played real tennis and was a member of Queen's Club.

His recreations included naval history, on which he had a large library of books, and modelling - making many scale models of famous sailing vessels and men o'war. He also had a large model railway and in his late 50s followed his sons in learning to fly.

He was very practical and his rehabilitation unit had Victorian treadle driven lathes on which his patients could be distracted from the tedium of leg rehabilitation exercises by turning objects on the lathes.

His career was anything but conventional. Despite working in rehabilitation and physical medicine, he gained his FRCS and became a physician who operated, a very unusual and perhaps lonely situation. He pioneered several surgical procedures for soft tissue

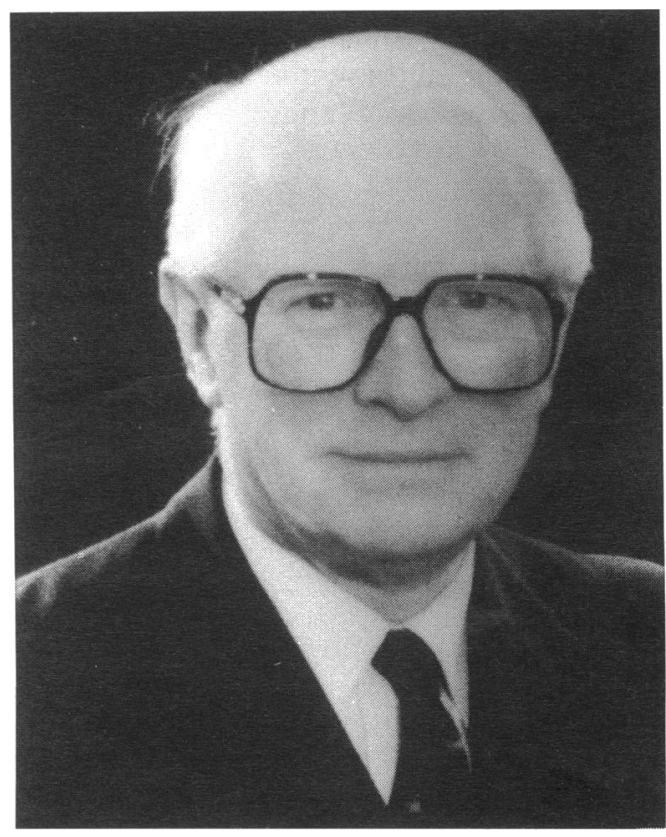

